\title{
LAS INFRACCIONES AL DERECHO DE AUTOR EN COLOMBIA. ALGUNAS REFLEXIONES SOBRE LAS OBRAS EN INTERNET Y LA INFLUENCIA DE NUEVAS NORMATIVAS
}

\author{
COPYRIGHT INFRINGEMENT IN COLOMBIA: SOME REFLECTIONS \\ ABOUTWORKS IN INTERNET AND THE INFLUENCE OF NEW \\ REGULATION
}

\author{
Olenka WoOlCotT* \\ Karen Isabel Cabrera Peña**
}

\begin{abstract}
RESUMEN: La tecnología ha transformado la manera como se crea y se adquiere la información que muchas veces está protegida por derechos de autor en entornos digitales e Internet, en consecuencia, hay nuevos casos de infracciones a los derechos de autor que, como es el caso de Colombia, no fueron previstos por el sistema de responsabilidad civil moderno. Este artículo tiene como propósito revisar cómo se viene abordando en Colombia la responsabilidad cuando ocurren infracciones a estos derechos en dichos entornos y reflexionar sobre el posible impacto de la incorporación de nuevas normativas al derecho de autor, en particular las que emanan del TLC firmado con Estados Unidos, con el fin de ilustrar la forma en que deben abordarse estas controversias.
\end{abstract}

Palabras clave: Derechos de autor, Internet, responsabilidad civil, infracciones.

ABSTRACT: Technology has transformed the way information of create and acquire the information that many times is protected by Copyright in digital and Internet environments as a result, there are new kinds of Copyright infringement, like happens in Colombia, that the civil liability system did not approach. This article pretends review how civil liability system in Colombia is working and made some reflections about the possible impact if had been incorporate a new Copyright regulation, in particular those that emanate from the signed FTA with the United States, in order to illustrate how these controversies should be addressed.

Keywords: Copyright, digital environment, Internet, infringements.

Doctora en Derecho de la Scuola Superiore di Studi Universitari (Italia). Profesora e investigadora en la Facultad de Derecho de la Universidad Católica de Colombia. Dirección postal: Calle 65, \# 7-49, Apto. 101, Chapinero, Bogotá. Dirección electrónica: olenka.woolcott@gmail.com

** Candidata a doctora en Derecho de la Universidad del Rosario (Colombia) Profesora e investigadora en el Departamento de Derecho de la Universidad del Norte. Dirección postal: Kra 52C N 90-125, Apto. 102D, Barranquilla. Dirección electrónica: kicabrerap@gmail.com.

El presente artículo es resultado del proyecto de investigación "Los retos del derecho privado contemporáneo en el contexto del debate constitucional y los nuevos desarrollos de la economía-fase 1” del Grupo de Estudio de Derecho Privado y Propiedad Intelectual de la Facultad de Derecho de la Universidad Católica de Colombia. 


\section{INTRODUCCIÓN}

El derecho de autor, que hace parte de la propiedad intelectual, protege aquellas creaciones humanas o bienes inmateriales que emanan del ingenio y talento que se concretan en obras literarias y artísticas. Estas creaciones tienen doble protección; por un lado, los derechos morales protegen las facultades personales que tiene el autor sobre la obra de manera perenne, mientras que los derechos patrimoniales otorgan prerrogativas de carácter económico que pueden ser transmitidas después de un tiempo determinado por la ley ${ }^{1}$.

El carácter especial de estos bienes ha hecho que existan leyes que regulen sus mecanismos de protección para su uso. Sin embargo, en Colombia estas aún no están tan desarrolladas. Este es el caso de la responsabilidad por infracciones a los derechos de autor en donde a pesar de que existen preceptos normativos que hacen referencia a la forma de indemnizar los perjuicios, estos no han sido efectivos para solucionar las controversias de este tipo e igualmente, la ley civil es muy general y no tiene en cuenta las particularidades de este derecho ${ }^{2}$.

En este orden de ideas, se esperaría que la responsabilidad civil por infracciones al derecho de autor se encuentre consagrada en una normativa que, aparte de prever las características que hacen especial esta clase de propiedad ${ }^{3}$, tenga en cuenta los avances tecnológicos y la masificación del uso del Internet, que además de tener dinámicas innovadoras y cambiantes de explotación de los derechos de autor, es el espacio en el que circulan más obras y en donde los derechos de autor son más vulnerados.

De la anterior problemática, este artículo realiza algunas reflexiones sobre el impacto de las nuevas tecnologías (Internet) en la responsabilidad civil cuando ocurren infracciones a estos derechos en dichos entornos. Posteriormente se estudia el posible impacto de la incorporación de nuevas normativas al derecho de autor en Colombia, en particular las que emanan del TLC firmado con Estados Unidos, con el fin de "dar luces" sobre la forma en que deben abordarse estas controversias según estos nuevos preceptos.

\section{IMPACTO DE LAS NUEVAS TECNOLOGÍAS DE LA INFORMACIÓN (INTERNET) EN EL DERECHO DE AUTOR}

La explotación comercial de las obras supone el derecho que tiene el autor de decidir sobre su destino ${ }^{4}$, puede optar por divulgarla para que un gran número de personas accedan a ella aun corriendo el riesgo de que sea copiado, deteriorado, enriquecido o criticado; o si desea, conservarla y retenerla con la esperanza de ser reconocido como autor único y creador de la obra hasta el punto de que no sea posible su divulgación 5 .

\footnotetext{
LIPSZYC (2006) pp. 21 y ss.

Morales (2007).

Artículo 61 de la Constitución Política de Colombia (1991) "El Estado protegerá la propiedad intelectual por el tiempo y mediante las formalidades que establezca la ley".

Ginsburg (1991) p. 176.

5 Rogel (2003) p. 64.
} 
Cualquiera que sea la decisión del autor, la obra podrá ser dada a conocer a través de medios análogos, cuando se materializa en un soporte físico como en un libro o por medios digitales cuando la obra existe en un medio virtual ${ }^{6}$, como ocurre en portales de descarga de música en donde la explotación es masiva, repetida y con posibilidades infinitas de copia.

Respecto a la obra en medios digitales, su explotación acarrea una serie de aspectos técnicos que son los que facilitan las relaciones entre los partícipes y permite el intercambio de la información que se encuentra en estos medios ${ }^{7}$. Estas dinámicas son las que hacen que obras puedan ser fragmentadas y transformadas para ser utilizadas total o parcialmen$\mathrm{te}^{8}$, lo que implica que se puedan dividir -a bajos o nulos costos- en cuantas partes se desee y las veces que sea posible hasta el punto de crear una nueva?.

De igual forma, cuando la obra está en circulación por medio de Internet ${ }^{10}$, que es un sistema que funciona a través de una gran cantidad de operadores informáticos y redes que son los que hacen se puedan transmitir datos entre ordenadores ${ }^{11}$, se desborda la capacidad de vigilancia con la que cuentan los órganos legales para protegerlas. Sin embargo, si no se divulgan se impediría que el crecimiento económico y el bienestar de la sociedad aumenten pues son generadoras de la innovación y la actividad creativa.

Lo anterior evidencia una problemática, que es determinar cuáles son las formas legítimas para la explotación de las obras en Internet sin que se vulneren derechos de autor, pues en muchos escenarios, donde se digitalizan, transmiten y/o mezclan estas, no hay claridad si están siendo copiadas y alteradas, y si dichas acciones son ilegales.

Por ejemplo, no hay claridad sobre la vulneración de derechos en la reproducción masiva de una obra en Internet pues no se podrá identificar la original debido a que las copias son de igual calidad que esta ${ }^{12}$. Además, la obra podrá ser utilizada por cualquier persona, sin que el autor o titular tenga su total vigilancia, ya que Internet no permite el control o la supervisión sobre la explotación de las obras ${ }^{13}$.

Ante lo anterior, algunos documentos legales han tratado de dar respuesta a estas situaciones. El primer gran precedente es el Acuerdo sobre los Aspectos de los Derechos de Propiedad Intelectual relacionados con el Comercio (ADPIC) de 1994 que nace de las negociaciones de los países del entonces GATT -ahora conocido como Organización Mundial del comercio (OMC) - que, entre otras cosas, señala en el artículo $7^{014}$ que los derechos

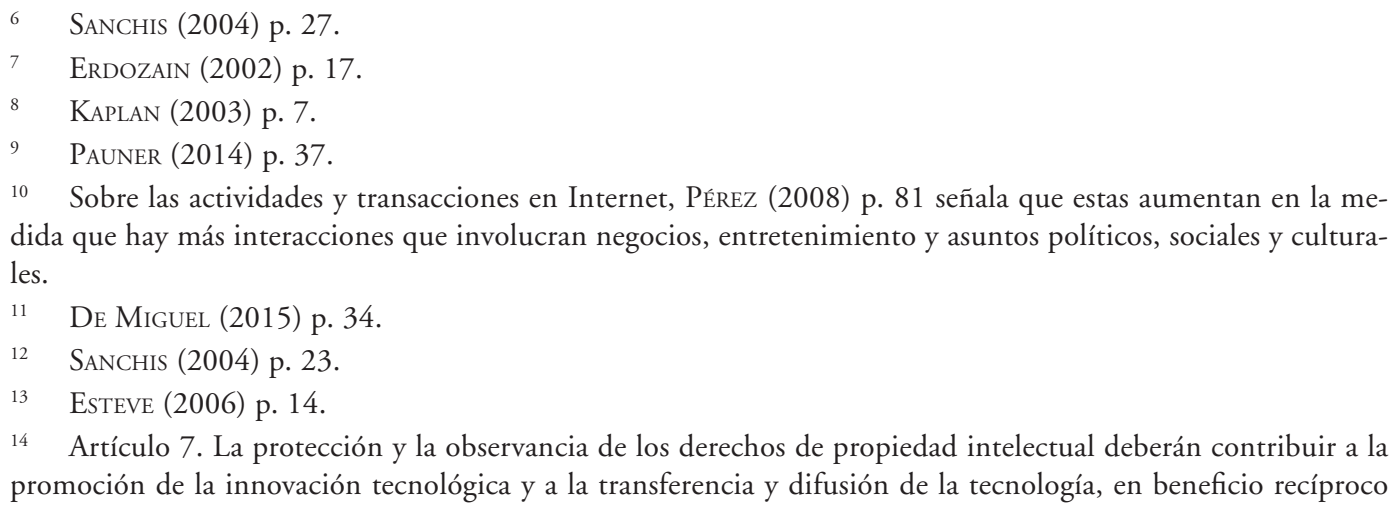


de propiedad intelectual deben promover la innovación tecnológica a favor de lograr un balance entre los productores y usuarios del conocimiento de tal forma que contribuyan al bienestar económico y social.

Por su parte, el artículo $10^{\circ 15}$ prevé que los programas de ordenador o software ${ }^{16}$ deben ser protegidos por la propiedad intelectual en cuanto a las disposiciones del Convenio de Berna ${ }^{17}$. De igual forma, el artículo $11^{\text {o18 }}$ impone el derecho de alquiler de los programas de ordenador y a las obras cinematográficas. La relevancia de los artículos radica en que se extiende la protección por derechos de autor a los programas de ordenador y las obras cinematográficas en derechos patrimoniales.

Si bien el mencionado tratado tuvo como fin regular unos avances tecnológicos como el software y proteger con medidas de observancia y ejecución los derechos de autor, asunto que Berna no hizo, quedaron por fuera temas como los procesos de digitalización de las obras y la expansión de las redes de Internet ${ }^{19}$, por lo que en 1996 nacen el Tratado de la $\mathrm{OMPI}^{20}$ sobre Derecho de Autor (TODA) y el Tratado de la OMPI sobre Interpretación o Ejecución y Fonogramas (TOIEF) que propenden -según sus dos principios ${ }^{21}$ - a velar por la protección de los autores y/o titulares ante la amenaza de la piratería digital y, que los Estados promulguen legislaciones que procuren el balance entre los derechos de los autores y los derechos al acceso de la información ${ }^{22}$.

de los productores y de los usuarios de conocimientos tecnológicos y de modo que favorezcan el bienestar social y económico y el equilibrio de derechos y obligaciones.

15 Artículo 10. 1. Los programas de ordenador, sean programas fuente o programas objeto, serán protegidos como obras literarias en virtud del Convenio de Berna (1971) (...).

16 Ромво (2015) p. 221 define Software a los programas, rutinas, lenguajes simbólicos e instrucciones que controlan el funcionamiento del hardware y que determinan su operación en múltiples equipos de tecnología para diversos objetivos y usos.

17 Convenio de Berna para la Protección de las obras literarias y artísticas de 1886, que nace para unificar criterios sobre la protección de obras literarias y artísticas, y plantear normas obligatorias, mínimas y específicas sobre el tratamiento del autor y sus obras para aquellos países que se hayan adherido a esta. Masouye (1978) p. 5.

18 Artículo 11. Al menos respecto de los programas de ordenador y de las obras cinematográficas, los Miembros conferirán a los autores y a sus derechohabientes el derecho de autorizar o prohibir el arrendamiento comercial al público de los originales o copias de sus obras amparadas por el derecho de autor (...). En lo referente a los programas de ordenador, esa obligación no se aplica a los arrendamientos cuyo objeto esencial no sea el programa en sí.

19 Alvarado (2002) p. 22.

20 Organización de la Propiedad Intelectual (OMPI), organismo de Naciones Unidas que tiene como finalidad el desarrollo el sistema mundial de propiedad intelectual Canaval (2008) p. 13.

21 Preámbulo TODA y TOIEF: (...) Reconociendo la necesidad de introducir nuevas normas internacionales y clarificar la interpretación de ciertas normas vigentes a fin de proporcionar soluciones adecuadas a los interrogantes planteados por nuevos acontecimientos económicos, sociales, culturales y tecnológicos (...).

Reconociendo el profundo impacto que han tenido el desarrollo y la convergencia de las tecnologías de información y comunicación en la creación y utilización de las obras literarias y artísticas (...).

22 Chelsey (2010) p. 5. 
Los artículos $4^{023}$ y $5^{\circ 24}$ del TODA, sobre los derechos patrimoniales, determinan como objeto de protección a los programas de ordenador y las bases de datos. Por su parte, el artículo $8^{025}$ sobre el derecho de comunicación pública, señala que puede realizarse por medios alámbricos o inalámbricos y el artículo $6^{026}$ establece el derecho de distribución de objetos intangibles, según el cual, el agotamiento del mismo dependerá de lo que estipulen los Estados.

El artículo $7^{027}$, sobre el derecho de arrendamiento, incluye la protección de los programas de ordenador, obras cinematográficas y las incorporadas en fonogramas y aclara la aplicación del derecho de reproducción en el entorno digital. Los artículos $11^{028}$ y $12^{029}$ regulan las medidas tecnológicas y de información sobre la gestión de derechos, como el compromiso de regular efectiva y adecuadamente las medidas tecnológicas de protección utilizadas por los autores ${ }^{30}$.

\footnotetext{
23 Artículo $4^{\circ}$. Los programas de ordenador están protegidos como obras literarias en el marco de lo dispuesto en el Artículo $2^{\circ}$ del Convenio de Berna. Dicha protección se aplica a los programas de ordenador, cualquiera que sea su modo o forma de expresión.

24 Artículo $5^{\circ}$. Las compilaciones de datos o de otros materiales, en cualquier forma, que por razones de la selección o disposición de sus contenidos constituyan creaciones de carácter intelectual, están protegidas como tales. Esa protección no abarca los datos o materiales en sí mismos y se entiende sin perjuicio de cualquier derecho de autor que subsista respecto de los datos o materiales contenidos en la compilación.

25 Artículo 8. (...) Los autores de obras literarias y artísticas gozarán del derecho exclusivo de autorizar cualquier comunicación al público de sus obras por medios alámbricos o inalámbricos, comprendida la puesta a disposición del público de sus obras, de tal forma que los miembros del público puedan acceder a estas obras desde el lugar y en el momento que cada uno de ellos elija.

26 Artículo 6. (1) Los autores de obras literarias y artísticas gozarán del derecho exclusivo de autorizar la puesta a disposición del público del original y de los ejemplares de sus obras mediante venta u otra transferencia de propiedad. (...).

27 Artículo 7. (1) Los autores de: (i) programas de ordenador; (ii) obras cinematográficas; y (iii) obras incorporadas en fonogramas, tal como establezca la legislación nacional de las Partes Contratantes, gozarán del derecho exclusivo de autorizar el alquiler comercial al público del original o de los ejemplares de sus obras (...).

28 Artículo 11. Las Partes Contratantes proporcionarán protección jurídica adecuada y recursos jurídicos efectivos contra la acción de eludir las medidas tecnológicas efectivas que sean utilizadas por los autores en relación con el ejercicio de sus derechos en virtud del presente Tratado o del Convenio de Berna y que, respecto de sus obras, restrinjan actos que no estén autorizados por los autores concernidos o permitidos por la Ley.

29 Artículo 12. (1) Las Partes Contratantes proporcionarán recursos jurídicos efectivos contra cualquier persona que, con conocimiento de causa, realice cualquiera de los siguientes actos sabiendo o, con respecto a recursos civiles, teniendo motivos razonables para saber que induce, permite, facilita u oculta una infracción de cualquiera de los derechos previstos en el presente Tratado o en el Convenio de Berna (...).

30 FICSOR (2002) p. 14
} 
Siguiendo con el TOIEF, el artículo $2^{\circ 31}$ incluye la transmisión a través de Internet como parte del derecho de publicación y comunicación pública de las obras ${ }^{32}$ y los artículos $7^{\circ}$ a $10^{\circ}$ otorgan protección a los artistas, intérpretes o ejecutantes para que gocen de derechos morales, derechos de radiodifusión y comunicación al público.

De la protección jurídica adecuada de elusión de medidas tecnológicas, el TOIEF en el artículo $18^{\circ 33}$, al igual que el TODA, estipula la protección a través de medidas tecnológicas efectivas. Similar situación sucede con el artículo $19^{\circ 34}$ que establece obligaciones a los Estados miembros sobre medidas para la gestión de derechos.

Se destaca entonces, como una de las novedades más significativas de estos tratados, que el derecho de alquiler no se aplique en los casos de un programa de ordenador cuando dicho programa no sea el objeto esencial para la utilización de la obra creada. Igualmente, se incorporara como una obligación para los Estados, regular los controles o medidas tecnológicas que utilizan los titulares de los derechos de autor para proteger sus obras ${ }^{35}$. Para finalizar, se logra el reconocimiento de los derechos morales de los artistas, intérpretes y ejecutantes.

De las normas en Colombia sobre la adecuación de la legislación para los entornos digitales, únicamente la Decisión 351 del Régimen Común sobre derecho de autor y derechos conexos de la Comunidad Andina de Naciones ${ }^{36}$ otorga protección al Software y a las bases de datos ${ }^{37}$, a pesar de que Colombia ratificó los Tratados de la OMPI, hasta la fecha no hay legislación nacional que regule y desarrolle esos temas.

Ahora bien, la Ley 23 de 1982 sobre derechos de autor y la Decisión 351 contienen una lista ilustrativa - no cerrada- de los derechos que posibilita adaptar y proteger aquellos que versan sobre las obras en entornos digitales ${ }^{38}$. Apoyando esta posición se encuentra la

31 Artículo 2. (...) (e) "publicación” de una interpretación o ejecución fijada o de un fonograma, la oferta al público de la interpretación o ejecución fijada o del fonograma con el consentimiento del titular del derecho y siempre que los ejemplares se ofrezcan al público en cantidad suficiente; 3 (f) "radiodifusión”, la transmisión inalámbrica de sonidos o de imágenes y sonidos o de las representaciones de estos, para su recepción por el público; dicha transmisión por satélite también es una "radiodifusión"; la transmisión de señales codificadas será "radiodifusión" cuando los medios de descodificación sean ofrecidos al público por el organismo de radiodifusión o con su consentimiento; (g) "comunicación al público" de una interpretación o ejecución o de un fonograma, la transmisión al público, por cualquier medio que no sea la radiodifusión, de sonidos de una interpretación o ejecución o los sonidos o las representaciones de sonidos fijadas en un fonograma (...).

32 Plaza (2002) p. 170.

33 Artículo 18. Las Partes Contratantes proporcionarán protección jurídica adecuada y recursos jurídicos efectivos contra la acción de eludir medidas tecnológicas efectivas que sean utilizadas por artistas intérpretes o ejecutantes o productores de fonogramas en relación con el ejercicio de sus derechos en virtud del presente Tratado y que, respecto de sus interpretaciones o ejecuciones o fonogramas, restrinjan actos que no estén autorizados por los artistas intérpretes o ejecutantes o los productores de fonogramas concernidos o permitidos por la Ley.

34 Artículo 19. Obligaciones relativas a la información sobre la gestión de derechos.

35 LIPSZYC (2004) p. 121.

36 Comunidad Andina de Naciones (2016) a la que pertenece Colombia y tiene como función "alcanzar un desarrollo integral, más equilibrado y autónomo, mediante la integración andina, suramericana y latinoamericana”.

37 Artículo 4. Del objeto de la protección.

38 Zapata (1998) p. 140. 
Sentencia del Proceso No. 24 IP de 1998 que reconoce la aplicación de los derechos patrimoniales a cualquier uso conocido o por conocer y la Sentencia del Proceso No. 177-IP2013 del Tribunal de Justicia de la Comunidad Andina que señala que los derechos morales engloban una serie de acciones que le permiten al autor hacer con su obra lo que él disponga, como decidir dónde la divulga.

Como se observa, en los últimos años los Estados han expedido algunos tratados y leyes nacionales con la finalidad de proteger, no solo las dinámicas propias de la era digital sino, los derechos de los autores/titulares respecto a sus obras y el de la sociedad de poder disfrutar de ellas. Si bien los avances normativos han aportado a la reglamentación del tema, aún existen retos que abordar en la medida que los avances tecnológicos siguen evolucionando.

Algunos de estos retos son: primero, la adaptación del derecho a las nuevas formas de creación y difusión de la obra de tal forma que se protejan los derechos de los autores y titulares; segundo, el control idóneo de los contenidos subidos en Internet para evitar conflictos jurídicos sobre vulneración a los derechos de libertad de expresión y la protección de los datos personales. Por último, la fijación de medidas eficaces para evitar la vulneración de los derechos de autor.

Al respecto, el sistema de responsabilidad civil se constituye en un mecanismo para prevenir infracciones a los derechos de autor y si se adecua a los entornos digitales para incentivar la capacidad creadora de los artistas y el goce de la innovación y la cultura en estos contextos.

\section{LA APLICACIÓN ACTUAL DEL SISTEMA DE RESPONSABILIDAD CIVIL FRENTE A LAS INFRACCIONES AL DERECHO DE AUTOR}

La institución de la responsabilidad civil adquiere un papel fundamental en la solución del conflicto de intereses que se genera a partir de la producción de un daño, y en esa medida, sus reglas cumplen un papel importante en el control de las actividades que tienen lugar en la sociedad ${ }^{39}$ cuando se trata de comportamientos en permanente evolución ${ }^{40}$. Si bien existe un interés de la víctima en que se repare integralmente el daño sufrido, por otro lado, la institución tiene entre otras funciones, una función preventiva de los daños que trasciende los intereses concretos involucrados en el caso para impactar en la sociedad ${ }^{41}$.

Se conocen normalmente como funciones de la responsabilidad civil la función compensatoria, la función preventiva y la función sancionatoria ${ }^{42}$. Si esta tiene como función principal la reparación de los daños y además, debe cumplir una función preventiva de los daños, corresponde a este aparte del trabajo determinar cuál es la aplicación que tiene la

\footnotetext{
39 El problema de la responsabilidad civil elaborado por los intérpretes consiste en la elección de los criterios por los cuales un determinado costo social es dejado sobre la víctima o trasladado de la víctima a otros sujetos. RоDотÀ (1964) p. 74.

40 HEINER (1986) p. 227.

41 En el sentido que ninguna función por sí sola puede explicar la compleja estructura de las reglas jurisprudenciales de la responsabilidad civil. Schuck (1991).

42 Ponzanelli (1992) pp. 243-297.
} 
institución en la actualidad, respecto a los daños que derivan de infracciones al derecho de autor.

Como es sabido, en todo supuesto de responsabilidad deben confluir el daño, el hecho generador del daño, la relación causal y el elemento fundante o la razón de la imputación de la responsabilidad, es decir, el criterio de atribución ${ }^{43}$. Trasladado el esquema de responsabilidad a los casos de infracciones al derecho de autor, se tiene que los elementos consisten, en el daño que resulta de la conducta infractora del derecho de autor, la relación causal que debe existir entre ambos elementos y en el criterio de imputación que debe determinarse en la ejecución de la infracción misma.

Sin perjuicio, de las dificultades probatorias de cada uno de los elementos de la responsabilidad, se puede observar que en las infracciones al derecho de autor surgen criterios o elementos de juicio que deben estar presentes cuando se trata de establecer la conducta infractora con relación a la reparación del daño.

\subsection{LA INFRACCIÓN AL DERECHO DE AUTOR COMO ELEMENTO DE LA RESPONSABILIDAD}

La infracción al derecho de autor consiste, como precisa Gautier, en "el hecho de utilizar públicamente, de cualquier manera, sin haber requerido el consentimiento previo, la obra ajena, que es objeto de una protección de acuerdo a la ley... En todo caso, la infracción existe cuando un autor ha reproducido la obra de otro" ${ }^{4}$. Se trata pues, de una actividad ilícita que se configura por la conducta que atenta contra el objeto de protección, es decir, el derecho que recae sobre la obra ${ }^{45}$.

Como se puede desprender, el énfasis está puesto en la conducta humana que vulnera el derecho de autor que tiene por objeto la protección de las obras. En este orden de ideas, corresponde recordar los requisitos para que proceda la protección autoral y una vez determinados, si tuviera lugar una conducta que vulnera el derecho tutelado por el régimen de derecho de autor, se configura la infracción al derecho de autor.

Según lo señalado, el derecho de autor protege las obras ${ }^{46}$, de las cuales derivan unos derechos morales y patrimoniales. La protección de los primeros es ilimitada en el tiempo, mientras que los segundos tienen una protección temporal ${ }^{47}$. Por último, el derecho no debe encontrarse en el campo de las excepciones y limitaciones al derecho de autor ${ }^{48}$. Estos elementos deben ser considerados al determinar si se produce una infracción al derecho de autor, lo que fija la ilicitud de la conducta que vulnera el derecho de autor ${ }^{49}$.

\footnotetext{
43 Un tratamiento completo sobre los elementos de la responsabilidad civil se aprecia en VISINTINI (1999); MONATERI (1998).

44 Gautier (2004) pp. 790-791.

45 Plata (2010) p. 101

46 LuCAS, \& LUCAS-SCHLOTER (2012) p. 88.

47 CARON (2013) p. 229.

48 Caron (2013) p. 330.

$49 \quad$ Plata (2010) p. 96.
} 
Verificada la existencia del derecho de autor sobre la obra ${ }^{50}$ procede la indagación sobre la configuración de la infracción al derecho de autor, lo que conduce a la determinación de la conducta ilícita como elemento del supuesto de responsabilidad civil consiguiente, indagación que presenta dificultades de comprensión y verificación a los fines de la determinación de responsabilidad.

\subsection{LA CONDUCTA ILÍCITA COMO ELEMENTO MATERIAL DE RESPONSABILIDAD Y LA} PRESUNCIÓN DE CULPA EN LA IMPUTACIÓN DE RESPONSABILIDAD

Cuando un sujeto edita una obra sin la autorización de su autor, incurre en la vulneración del derecho moral de divulgación ${ }^{51}$, o si coloca su nombre a una obra cuando no es de su autoría, acto del cual derivarán a su favor los derechos morales y patrimoniales, es evidente que se trata de una infracción al derecho de autor. Ante una conducta de evidente trasgresión de la norma, se piensa que se está ante una infracción al derecho de autor, y en este sentido, la indemnización de los daños derivados resulta claro si se mira con el prisma del Copyright Act de Estados Unidos, donde la víctima debe probar que realizó la copia de la obra y que dicha copia no era permitida ${ }^{52}$.

En los sistemas de tradición latina, como el colombiano, la indemnización de los daños complica el examen para las infracciones de derecho de autor, si se parte de la consideración de la cláusula general de la responsabilidad civil por culpa como consagra en el artículo $2341^{\circ}$ del Código Civil, heredero de su correspondiente en el Code Civil de 1804. Conforme al citado principio de responsabilidad, la víctima tiene que probar la culpa del causante del daño para que prospere su pretensión indemnizatoria. En efecto, la citada norma contiene el criterio de imputación subjetivo, la culpa, de lo cual se desprendería que a la conducta ilícita del infractor del derecho de autor debería sumársele la prueba del elemento culpa.

En otros términos, de acuerdo a una lectura textual de la norma, se podría entender que, además del elemento material de la conducta, sería necesaria la prueba de la culpa para los fines de la imputación de responsabilidad. Sin embargo, esta lectura no es adecuada para la imputación de responsabilidad por infracción al derecho de autor e incluso, configuraría un obstáculo a la lucha contra sus infracciones, en el sentido que el infractor de la norma podría alegar su ignorancia, buena fe o falta de intención en la vulneración para exonerarse. De allí que "si la obra ha sido explotada, sin autorización, se ha configurado la infracción" 53 .

En esta línea de pensamiento, la doctrina francesa ha remarcado que para los fines de una sanción civil, como lo es la responsabilidad civil, a diferencia del derecho penal, no se

\footnotetext{
50 De los requisitos para que la conducta sea considerada susceptible de generar responsabilidad civil, ha explicado Plata, los elementos que deben concurrir, partiendo de la determinación de la existencia de una obra protegida por el derecho de autor, la afectación sea de derechos patrimoniales o morales, que no haya expirado el plazo de protección para los primeros y que no interfiera una excepción o limitación al derecho de autor. PLATA (2010) pp. 111-145.

51 LipszyC (2006); BerCovitz (2003).

52 Schechter \& Thomas (2003) pp. 169-177.

53 CA Paris, 31 de octubre 2000. Comm. Com. Électr (2001).
} 
requiere para la configuración de la infracción de derecho de autor, el elemento "moral" o subjetivo de la conducta, es decir, el dolo o la culpa. Desde esta óptica, si la conducta es ilícita, corresponde aplicar las sanciones a la infracción, si no existe la calidad de ilicitud, no cabe hablar de una infracción ${ }^{54}$.

Según la jurisprudencia francesa, son los elementos del caso los que permiten presumir las similitudes entre la obra original y las copiadas ilegalmente, de igual forma la probabilidad de la mala fe del demandado al cometer la infracción al derecho de autor. Es así como son las circunstancias del caso las que permiten a los jueces inferir la mala fe del infractor cuando este tiene la condición de un profesional. Así, "de un hecho conocido, la gran semejanza entre dos obras, se puede inferir un hecho desconocido, lo que constituye una definición de la presunción" 55 .

La presunción admite prueba en contrario, la que puede consistir de un lado, en la prueba de que la coincidencia de las obras confrontadas es fortuita, lo que representa una situación muy excepcional, y de otro lado, puede consistir en un error legítimo del demandado ${ }^{56}$, lo que será apreciado por el juez, teniéndose en cuenta que debe haber un mínimo de diligencia en quien realiza una obra para informarse de la existencia de otra u otras obras similares.

En otros términos, la jurisprudencia francesa ha aplicado en estos casos el principio según el cual los hechos hablan por sí mismos, res ipsa loquitur ${ }^{77}$. Por su parte, la doctrina francesa ha explicado que la tendencia jurisprudencial se encuentra a favor de las víctimas de violación del derecho de autor, lo que se concilia con las políticas de represión de las infracciones de estos derechos ${ }^{58}$.

En este marco de ilicitud de la conducta infractora, adquiere relevancia el supuesto de la responsabilidad por infracción al derecho de autor como un supuesto sui generis, en el cual, el régimen de la responsabilidad civil debe adaptarse a las particularidades de la propiedad intelectual, entre las cuales destaca su esencial carácter inmaterial, del que precisamente se desprenden las dificultades de valoración de los daños que se producen por la infracción y al mismo tiempo, la imposibilidad de razonar a partir de un valor de reposición del derecho afectado a los fines de la reparación ${ }^{59}$.

En efecto, la inmaterialidad del bien tutelado en el derecho de autor exige innovar ${ }^{60}$, lo que explica la necesaria adaptación del régimen vigente de la responsabilidad civil a este especial supuesto de responsabilidad, el cual tiene como requisito ineludible la infracción, es decir, la conducta ilícita que vulnera el derecho de autor y lleva en sí misma el ingrediente subjetivo del supuesto de responsabilidad civil.

Desde esta perspectiva, no cabe exigir a la víctima la prueba adicional de la culpa, sino más bien debe presumirse de la vulneración del derecho de autor. Bajo este enten-

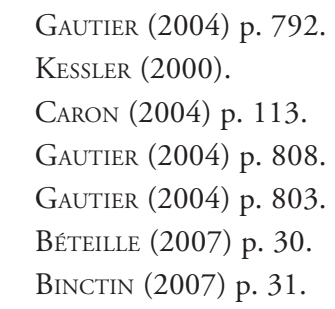


dimiento y de acuerdo a la expresa remisión a las normas generales que hace la Ley 23 de 1982, vale decir, al régimen de responsabilidad del Código Civil, para la imputación de la responsabilidad debe bastar la conducta que vulnera un derecho moral o patrimonial de autor para que se configure el elemento material del supuesto de responsabilidad. Dicha conducta puede consistir en una acción o una omisión ${ }^{61}$.

Si la conducta que vulnera el derecho de autor configura la infracción y esta es un elemento del supuesto de responsabilidad, se colige que dicha conducta no requiere de la prueba del criterio subjetivo de imputación, toda vez, que el elemento subjetivo se presume de acuerdo a las circunstancias de la infracción. Se puede apreciar que de esta manera, se alcanza una solución cercana a la que ofrece el derecho del Copyright ${ }^{62}$, de matriz anglosajona ${ }^{63}$, donde el examen que conduce a la determinación de la infracción prescinde de toda culpa o dolo como elemento que cualifica la conducta infractora.

\section{CONTROVERSIAS EN EL SISTEMA DE RESPOSABILIDAD CIVIL COLOMBIANO CUANDO SE TRATA DE INFRACCIONES AL DERECHO DE AUTOR EN INTERNET}

Como se anotó anteriormente, para que pueda configurarse la responsabilidad civil se necesita de la concurrencia de ciertos elementos, cuya falta determina que no se pueda constituir la obligación de indemnizar. En el caso de Colombia, existen además, unos lineamientos internacionales como los Tratados de la OMPI y el ADPIC que han señalado algunas directrices sobre cómo debe regularse la responsabilidad civil por infracciones al derecho de autor. En el ámbito nacional han sido la Decisión Andina 351 y la Ley 44 de 1993 las leyes que se aplican para determinar los perjuicios relativos a las infracciones al derecho de autor cuando se trata de daños materiales.

En el entorno digital la protección del derecho de autor funciona diferente a la de los medios análogos, porque la fijación de la obra no se encuentra en un soporte físico por lo cual, no hay claridad sobre el momento en que empieza la protección. Por otro lado, las obras no circulan de la misma forma que en los medios tradicionales, por el contrario van andando "en una nube" y hospedándose -la totalidad o parte de ellas- en ordenadores sin que pueda haber un control de ellas.

Según lo anterior habrá responsabilidad civil, por ejemplo, en los programas informáticos como P2P (Peer to Peer) y las redes de Messenger de mensajería instantánea o Skype de telefonía, que permite la comunicación entre los usuarios y a la vez descargar y compartir archivos digitales de todo tipo ${ }^{64}$ cuando se realizan estas acciones sin la autorización del autor o sin pagar licencias por su uso. En otros escenarios, como en la exposición de datos a través de las redes como Facebook o Instagram podría haber responsabilidad civil por parte

\footnotetext{
61 Plata (2010) p. 103

62 Schechter, Roger \& John (2003)

63 Se trataría de un aspecto que evidencia más que una oposición de principio, una aproximación de hecho entre el sistema tradicional del derecho de autor y el Copyright. Benahamou \& FarChy (2009) p. 22

64 León y Valera (2015) p. 7
} 
de quien no pide autorización para utilizar el material o lo hace sin remuneración al titu$\operatorname{lar}^{65}$.

En Colombia, debido a la ausencia de un sistema de responsabilidad civil especial para las infracciones al derecho de autor y menos que tenga en cuenta las actividades que se realizan en Internet, los presupuestos para imputar el daño serán los mismos que se utilizan para los medios análogos, que a su vez tienden a regularse bajo los presupuestos generales de la responsabilidad civil del derecho común ${ }^{66}$. Se debe demostrar el detrimento, el elemento subjetivo que acompaña a la conducta ilícita y el nexo causal, componentes sobre los cuales fueron instaurados los criterios de determinación del daño material de la Ley 44 de 1993.

De manera general, los inconvenientes para la imputación de responsabilidad bajo la determinación del monto del daño material en que se basa la responsabilidad subjetiva emanan de la autorregulación de las redes y de sus participantes, ya que probar los elementos es más difícil cuando una sola conducta ilícita involucra la vulneración de varios derechos de autor que deben ser apreciados separadamente o cuando la delimitación temporal y espacial de donde se cometió la infracción no es determinable ${ }^{67}$.

Piénsese, por ejemplo, en los casos en que se reproduce y comparte por una red social, sin autorización del titular y/o autor, información que es protegida por derechos de autor. Este acto en medios análogos implicaría únicamente la vulneración del derecho de reproducción, mientras que en entornos digitales representa una infracción de derechos como el de reproducción y comunicación pública, donde no es claro si un derecho es consecuencia del otro o si la infracción no podría realizarse sin que haya la vulneración de los dos derechos ${ }^{68}$.

Además, las interacciones por medios digitales no son simples actos de comunicación, sino que implican el almacenamiento, reproducción y distribución de contenidos que están protegidos por el derecho de autor y, en esta medida, la no autorización de uso de la obra puede desencadenar unas conductas ilícitas como la reproducción no autorizada, puesta a disposición de la obra por medios electrónicos ${ }^{69}$, hasta romper medidas tecnológicas de protección.

Aterrizando el asunto en los escenarios de responsabilidad extracontractual -que son los más comunes en infracciones al derecho de autor en Internet- la responsabilidad civil se genera con la distribución de obras por medio de blogs, redes sociales, chats y mensajería sms/mms sin autorización del autor/titular como si fuese una práctica común del comercio y dado que tampoco existe ningún vínculo legal entre el usuario y el autor/titular, es más difícil determinar el daño ${ }^{70}$.

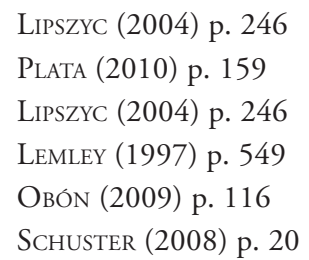


Ahondando en el artículo $57^{\circ}$ de la Ley 44 de 1993 que establece los elementos con los que actualmente cuenta el juez para determinar el monto del daño en derechos de autor, a saber, el valor comercial de los ejemplares producidos o reproducidos sin autorización, el valor que hubiere percibido el titular del derecho de haber autorizado su explotación y el lapso durante el cual se efectuó la explotación ilícita, se evidencia algunas dificultades al momento de incorporarlos en los medios digitales.

Por ejemplo, el criterio del valor comercial de los ejemplares producidos o reproducidos sin autorización, no es viable para el demandante si la reproducción de la obra se hizo de forma gratuita y el infractor no generó ingresos de la conducta ilícita -lo que es muy común en Internet- debido a que no es posible saber el valor que hubiere derivado al titular de haber autorizado el uso, y por tanto, la imposición de la indemnización no estaría acorde con el daño.

En el caso de que el infractor haya generado ingresos por la conducta ilícita, este monto no se equipara al valor de la comercialización de la obra original si se tiene en cuenta que la digitalización de las obras hace que estas se copien y reproduzcan a muy bajos costos. En este caso, la función disuasiva de la responsabilidad no se cumple.

En el criterio del valor que hubiese obtenido el titular al autorizar la explotación de la obra, es decir, el lucro cesante, la determinación del monto del daño no sería idónea si se considera que en Internet es complicado saber las clases de usos ilegales que se hicieron sobre la obra, y este punto es determinante para tasar los ingresos que habría recibido el autor/titular de haber autorizado dicha utilización. Esto sucede a menudo cuando se comparten archivos musicales o imágenes, en el caso de una canción esta puede ser transformada, fragmentada y compartida sin autorización del autor/titular muchas veces una vez se difunde en Internet ${ }^{71}$.

La misma dificultad ocurre con el criterio que tasa el daño según el período durante el cual se efectuó la explotación ya que las operaciones en Internet ocurren de manera rápida, y en muy poco tiempo se pueden vulnerar varios derechos de diferentes formas y muchas veces.

Para recrear las dificultades de la determinación del daño según los criterios de la Ley 44 , se puede pensar en las infracciones a través de los sistemas P2P (Peer to Peer) que se presentan generalmente cuando se hace intercambio y montaje de archivos digitales que contienen obras o prestaciones protegidas por derechos de autor y/o derechos conexos, como música, videos, softwares, fotografías y textos, sin la autorización del autor/titular ${ }^{72}$.

Como se mencionó, P2P es un sistema de intercambio de archivos que está desarrollado sobre un programa informático que permite a los usuarios disponer y acceder, entre ellos, a archivos digitales que hayan sido almacenados en carpetas compartidas que se crean en los discos duros de los ordenadores de los integrantes del programa. Dado que en estas redes no existen servidores centrales y los clientes que se conecten entre ellos, actúa cada

\footnotetext{
EsTEVE (2006) p. 17.

Ribera (2009) p. 38.
} 
uno como servidor y cliente ${ }^{73}$, es muy difícil rastrear los usos ilegales que se hacen, las veces que se hacen y el lugar geográfico donde se llevan a cabo.

Si bien no todo intercambio a través de esta red infringe los derechos de autor como por ejemplo, cuando la obra bajo dominio público, está cobijada bajo una excepción o limitación, o incluso cuando el intercambio está sujeto al pago de una licencia o precio; lo cierto es que la mayoría de las descargas e intercambios por P2P se hacen sin ningún reconocimiento del autor y menos pagando una remuneración ${ }^{74}$.

Entre los conflictos que suscitan determinar -entre otras cosas- cuántos actos ilícitos de reproducción se hicieron o cuántas copias ilegales se encuentran navegando en Internet, se evidencia que la legislación en Colombia solo dispone del supuesto de responsabilidad por culpa del régimen general previsto en el Código Civil, con énfasis en la función compensatoria de los daños y cuya aplicación determina la prueba de los elementos de responsabilidad a cargo de la víctima, incluyendo la culpa, perspectiva que no es idónea para los casos de responsabilidad por infracciones al derecho de autor en Internet.

Lo anterior se constata en un sinnúmero de estudios que se han realizado en países con similar sistema de determinación del monto del daño al de Colombia, en donde se revela que no se han podido controlar las infracciones al derecho de autor en Internet, por el contrario, siguen en aumento. Por ejemplo, según la Federación para la defensa de la Propiedad intelectual (FAB) de España en el estudio realizado en el año 2014 por el Observatorio de piratería y hábitos de consumo de contenidos digitales, el acceso ilegal digital -valorado en volúmenes- corresponde a 4.455 millones de contenidos pirateados que equivalen a un aproximado de 23.265 millones de euros ${ }^{75}$.

El estudio de American Chamber of Commerce of Mexico (AMCHAM) y el Centro de Investigación para el Desarrollo (CIDAC) del año 2015 titulado "Estudio sobre la piratería: El mercado sombra en México" concluyó que en el año 2014, el mercado sombra de la piratería supuso para el país una pérdida de más de 2.600 millones de dólares, sin contar el valor de las mercancías confiscadas, las pérdidas de empleo y de ingresos y los impactos en la salud y la seguridad de los consumidores ${ }^{76}$.

La investigación concluye que el impacto por la piratería equivale a más del $28 \%$ del presupuesto total de 2015 del Consejo Nacional de Ciencia y Tecnología (CONACYT), 34 veces más que el presupuesto de 2015 del Instituto Mexicano de la Propiedad Industrial (IMPI) y una pérdida de ingresos de poco más 363,9 millones de dólares en concepto del impuesto al valor agregado (IVA).

Por último, la investigación de la Alianza contra la Piratería de Televisión Paga, sobre la situación de la piratería de la Televisión en Suramérica de enero de 2016, señala que en el año 2015, durante un mes, aproximadamente 8.7 millones de usuarios de Latinoamérica realizan un promedio de 30 visitas a los 20 sitios principales de P2P lo que equivaldría a

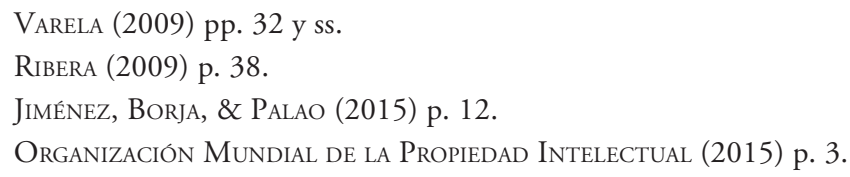


casi 379 millones de horas de TV lo que ocasiona una pérdida de 4.5 dólares por hora ${ }^{77}$. El estudio colige que a medida que se genera un aumento en los índices de acceso a Internet y en sus velocidades, los titulares de derechos se topan con niveles de uso ilegal aún más elevados, sin que se verifique un cambio significativo en relación a las actitudes del público con respecto a la piratería.

De todo lo anterior se puede concluir que la era digital ha repercutido en el estudio de la responsabilidad civil, toda vez que la concepción de la responsabilidad en sentido material que contiene la legislación en Colombia no es suficiente para asegurar la reparación de los daños en derechos de autor ocasionados en estos contextos por lo que es necesario considerar la aplicación de principios y criterios de cuerpos normativos internacionales.

\section{LOS COMPROMISOS ADQUIRIDOS POR COLOMBIA SOBRE LA OBSERVANCIA DE LOS DERECHOS DE AUTOR CON EL FIN DE ESTAR ACORDE CON EL DERECHO INTERNACIONAL}

La evolución de la normativa internacional en materia de los derechos de propiedad intelectual presenta unos desafíos para las legislaciones nacionales en términos de plantear una necesaria adecuación de la normatividad tradicional del derecho de autor, fundamentalmente del modelo de la Convención de Berna de 1886, caracterizada por la ausencia de normas que garanticen una efectiva protección y observancia de estos derechos, frente a los nuevos lineamientos de corte fundamentalmente comercial que desde hace unas décadas permean el tratamiento del derecho de autor y que han determinado un cambio en el paradigma, en el sentido de dejar atrás una visión romántica del derecho de autor ${ }^{78}$ para adoptar una visión utilitarista, de allí que surjan pronunciamientos que hablan de una crisis del derecho de autor ${ }^{79}$.

La nueva imagen de carácter comercial que permea en la actualidad el tratamiento del derecho de autor, puede apreciarse con claridad en el plano internacional, inicialmente, en el Acuerdo que estableció la Organización Mundial del Comercio y que contiene un anexo con cláusulas referidas a los Derechos de Propiedad Intelectual relacionados con el Comercio $^{80}$, conocido por sus siglas como ADPIC ${ }^{81}$ o TRIPS en inglés. Colombia tuvo interés en integrarse al mencionado tratado, debido a la importancia que adquirirían los derechos de propiedad intelectual en el marco de una apertura de los mercados, considerando además, su especial interés por ser parte de la $\mathrm{OMC}^{82}$.

\footnotetext{
Alianza contra Piratería de Televisión Paga (2016) p. 3.

Sirinelli (2000) p. 194.

Bensamoun (2010) p. 4.

80 Sobre una crítica al ADPIC en el sentido que la dimensión humana que es primordial en el derecho de autor, no está presente en el referido acuerdo internacional. GAUBIAC (1995) p. 7.

81 El ADPIC fue ratificado por Colombia el 31 de marzo de 1995, mediante ley $N^{\circ} 170$ de 1994 . Sobre las características del ADPIC véase IzQUIERdo Palacio (2011).

82 Woolcott \& Flórez (2015) p. 102.
} 
El ADPIC representa un primer paso en el proceso de globalizar ${ }^{83}$ un régimen de observancia de los derechos de propiedad intelectual, en mérito a lo cual se pueda garantizar la fluidez y el desarrollo del comercio.

En este sentido, el artículo 45 del ADPIC faculta a las autoridades judiciales para ordenar que el infractor pague al titular del derecho de propiedad intelectual un resarcimiento adecuado ${ }^{84}$ para compensar el daño que este haya sufrido por la infracción que fue causada "a sabiendas" o "por motivos razonables" de conocimiento. Asimismo, la norma confiere la facultad a las autoridades judiciales para que concedan una reparación por concepto de "beneficios" y/o resarcimiento por perjuicios reconocidos previamente (daños preestablecidos), aun cuando el infractor, no sabiéndolo o no teniendo motivos razonables para saberlo, haya desarrollado una actividad infractora.

Esta línea de énfasis en la observancia de los derechos de propiedad intelectual se refleja en un momento posterior, en los textos de los tratados de libre comercio celebrados por Estados Unidos. Es así que el Tratado de Libre Comercio (TLC) celebrado entre Colombia y Estados Unidos ha previsto un régimen de indemnización de daños por infracción a los derechos de propiedad intelectual que no se pronuncia sobre un criterio específico de imputación de responsabilidad, y sí cambia el sentido tradicional y fundamental que caracteriza la institución de la responsabilidad civil, inspirada en el principio de reparación integral de los daños.

En efecto, el artículo 16.11.7 del referido Tratado faculta a las autoridades juridiciales a ordenar al infractor que le pague al titular del derecho una indemnización adecuada para compensarlo por los daños sufridos como resultado de la infracción. Lo anterior, debe agregarse a dicho monto indemnizatorio en los casos de infracciones al derecho de autor o derechos conexos, y en las falsificación de marcas, deben agregarse "las ganancias obtenidas" por el infractor imputables a la infracción que no fueron consideradas en la determinación de la mencionada "indemnización adecuada".

Como se observa del referido texto del TLC, el interés se ha concentrado en la determinación de un monto indemnizatorio por la conducta infractora del derecho de propiedad intelectual, basado fundamentalmente en dos conceptos, una indemnización adecuada y los beneficios obtenidos por el infractor.

Sin duda, que la intención del TLC ha sido no acoger el principio de reparación integral de los daños que supone una valoración de estos "efectivamente" sufridos por la víctima, por ello, se han querido superar los problemas probatorios que existen sobre todo en materia de los intereses vulnerados en el campo del derecho de autor y por ello, la consagración de una fórmula muy flexible y librada a la discreción del juzgador, como es la "indemnización adecuada", que ya está consagrada como se vio anteriormente, en el ADPIC de 1994.

83 Matthews (2002).

84 La fórmula del "resarcimiento adecuado" configura una expresión tan amplia como discrecional para el juez que de acuerdo a ella y al contexto del ADPIC, no se encuentra condicionado por el tradicional principio de la reparación integral de los daños, considerándose además que este principio no rige el sistema de torts de los Estados Unidos. Dicho concepto se encuentra también en la Decisión Andina 351 de 1993. Sobre el espíritu armonizador del ADPIC frente a los sistemas de civil law y common law. Woolcott \& FlóreZ (2015) p. 141. 
En esta fórmula indemnizatoria cabe tener en cuenta los daños que se puedan probar en el proceso por parte de la víctima, pero también cabe la consideración de otros elementos de juicio que el juzgador puede entender pertinentes para la fijación del correspondiente monto indemnizatorio. De esta manera, la valoración de los daños no queda limitada al daño efectivamente producido y lo que es más difícil aún en el campo de la propiedad inmaterial, al daño efectivamente probado por la víctima.

La misma tendencia separatista en relación al principio de reparación integral se manifiesta en la incorporación de un concepto punitivo de la indemnización, como es el de las "ganancias" obtenidas por el infractor e imputables a la infracción, siempre que no fueran tenidas en cuenta por el juzgador en la determinación de la "indemnización adecuada”. Se entiende la última precisión toda vez que no cabe duplicar el concepto indemnizatorio, pues si las "ganancias" fueron uno de los elementos considerados en la fijación de la indemnización adecuada, mal puede volvérsele a considerar para incrementar el monto indemnizatorio.

De modo distinto, lo que se puede apreciar, en contraste con la valoración de los daños bajo la perspectiva tradicional de la responsabilidad civil, es que el TLC faculta al juzgador a incrementar la suma indemnizatoria con el concepto de las "ganancias", el cual, no corresponde a la reparación del daño efectivamente producido.

En efecto, "las ganancias" del infractor o beneficios ilícitos, constituyen un concepto adicional que no se relacionan con los daños que haya sufrido la víctima de la infracción, toda vez que están referidos más bien al causante del daño, el infractor. El hecho que el infractor haya obtenido unos beneficios económicos con el acto de infracción cometido, no determina que la víctima sufra más o menos, pues esas "ganancias" no repercuten en el patrimonio de la víctima de la infracción al derecho de autor ${ }^{85}$.

Se trata entonces, de un elemento de juicio que ha contemplado el TLC con ánimo sancionador para el infractor de los derechos de propiedad intelectual, por ende, de la propia composición de la indemnización se puede desprender un sentido punitivo y al mismo tiempo, preventivo de los daños frente a potenciales infractores de la propiedad intelectual.

Adicionalmente, el TLC ha contemplado una "indemnización preestablecida" que según el texto del Tratado, las partes deben prever en sus respectivos ordenamientos para que pueda servir a los jueces como una alternativa ante la fijación de una "indemnización adecuada" o basada en los daños reales. De acuerdo al espíritu preventivo que el Tratado reconoce a la indemnización, dichas sumas predeterminadas deberán consistir en un monto suficiente como para ejercer el fin disuasivo que persigue el régimen indemnizatorio.

85 Un examen similar pero con relación a la ley francesa del 29 de octubre de 2007, por la cual, se incorpora en el derecho de autor francés la figura de los "beneficios ilícitos" en el cómputo de la indemnización por infracción al derecho de autor. PASSA (2006). 


\section{LA FUNCIÓN DE REPARACIÓN Y LA FUNCIÓN PREVENTIVA DE LA RESPONSABILIDAD EN LOS CASOS DE INFRACCIONES AL DERECHO DE AUTOR}

Si tradicionalmente se reconoce a la función compensatoria de los daños como aquella función que determina la naturaleza de la institución de la responsabilidad civil, no menos cierto es que la función preventiva de los daños tiene un papel de importancia entre los objetivos de la institución.

La incursión de Internet en el campo del derecho de autor ha permitido retomar el debate sobre las funciones de la responsabilidad civil y precisamente, para el caso de los daños que derivan de las infracciones al derecho de autor, induce a preguntarse si corresponde reforzar la función preventiva de los daños al mismo tiempo que una función punitiva de la responsabilidad.

En efecto, la facilidad y velocidad con las que pueden circular los contenidos en Internet ha comportado un incremento de las ocasiones para que se cometan infracciones a los derechos de autor, de allí la necesidad de articular mecanismos y medidas de control de quienes tienen a su cargo la gestión de dichos contenidos. Si el entorno digital ha multiplicado las infracciones al derecho de autor, tal como se muestra en el apartado precedente, la respuesta desde la institución de la responsabilidad civil no puede fijarse solo en la función compensatoria de los daños. En efecto, además de la reparación de los daños, el sistema jurídico debe buscar un énfasis en la función preventiva y es entonces, que el reconocido "principio de precaución" 86 puede encontrar una aplicación fecunda en el campo de la protección del derecho de autor y de modo particular, ante las infracciones que tienen lugar a través de Internet.

Precisamente, la jurisprudencia francesa representa un caso paradigmático de cómo puede determinarse la responsabilidad de los proveedores de servicios de Internet que incurren en una infracción al derecho de autor, en base al criterio de imputación subjetivo -como es la culpa- a través de la exigencia de un comportamiento diligente en la verificación de la licitud de los contenidos que se alojan en los sitios web y en el cuidado necesario al momento de la celebración de los contratos con los beneficiarios del espacio.

De esta manera, los jueces franceses son conscientes de la necesidad de prevenir antes que punir ${ }^{87}$. En este sentido, una sentencia del Tribunal de París de 1998 afirmó lo siguiente: "El proveedor de servicio de un sitio Internet tiene la obligación de velar por la moral de aquello que alberga... y en respeto de las leyes y reglamentos y de los derechos de terceros. Para poder exonerarse de responsabilidad, aquel tendrá que justificar las obligaciones a su cargo, especialmente, en cuanto a la información al huésped de respetar... el derecho de autor" ${ }^{\prime 8}$.

Como se puede observar, la jurisprudencia francesa mostró tener una posición de rigor frente a la responsabilidad de los prestadores de servicio en Internet. Sin embargo, ha

\footnotetext{
Desideri (2000) p. 238.

87 Gautier (2004) p. 808.

88 Mallet-Poujol (1999) p. 638.
} 
sido contradicho por los postulados de los sucesivos textos legislativos europeos, como es el caso de la Directiva sobre Comercio electrónico de 8 de junio de 2004, y la posterior ley francesa de 21 de junio de 2004, dispositivos que han contemplado una fórmula negativa de la responsabilidad de los prestadores de servicio de Internet, en el sentido de precisar "que no son responsables" en un vasto campo que establece la ley.

De esta manera, los artículos 14 y 15 de la citada Directiva rechazan la existencia de una "obligación general de vigilancia" a cargo de dichos prestadores de servicios y en cambio, exigen la prueba de un "conocimiento efectivo" de la infracción, lo que constituye una tarea probatoria que pesa sobre la víctima ${ }^{89}$. En otros términos, la normativa europea, al igual que su similar estadounidense ${ }^{90}$, tiende a no responsabilizar a los prestadores de servicios de Internet, lo que será objeto de una interpretación restrictiva por parte de los jueces franceses.

Por su lado, se ha podido apreciar, con relación al TLC entre Colombia y Estados Unidos, que el texto refleja un énfasis en la observancia de los derechos de propiedad intelectual, lo que es coherente con la línea trazada desde la época del ADPIC de 1994. En este orden de ideas, el TLC pone a disposición del sistema colombiano un marco normativo innovador respecto a su derecho tradicional de la responsabilidad, en el sentido de contemplar unas directivas para determinar la indemnización de los daños por infracción al derecho de autor, las cuales priorizan las funciones preventiva y punitiva de la responsabilidad civil.

\section{CONCLUSIONES}

La responsabilidad por infracción al derecho de autor se encuentra bajo los alcances de la cláusula general de la responsabilidad civil que está contenida en el artículo $2341^{\circ}$ del Código Civil del sistema jurídico colombiano y su aplicación resulta confirmada por la remisión a las normas generales que hace la Ley 23 de 1982, que es la ley de Protección de Derechos de Autor. Sin embargo, la referida norma general no contiene pautas sobre cómo puede darse dicha aplicación a los casos de daños derivados de infracciones al derecho de autor, lo que constituye precisamente una tarea que se traslada a la jurisprudencia.

El aporte de las reflexiones provenientes del Derecho Comparado, tales como las que provienen de la doctrina y jurisprudencia francesas, pueden constituir un referente para los jueces colombianos, quienes deben interpretar la norma del Código Civil y adecuarla a los casos de infracciones al derecho de autor, de lo cual, se derivará la configuración de un supuesto de responsabilidad sui generis para las infracciones de este tipo.

De esta manera, los jueces tendrán que considerar las características especiales de la conducta ilícita y la eventual aplicación de una presunción de culpa del infractor. Por otra parte, es de anotar que, no obstante existir ciertas dificultades para la determinación del elemento material y subjetivo de la responsabilidad por infracción al derecho de autor,

\footnotetext{
89 Albrieux (2004).

90 Se trata de una línea trazada en la ley estadounidense de la Digital Millennium Copyright Act, DMCA, 17 USC 101 note, Public Law 105-304, October 28, 1998. WoolcotT \& Flórez (2014) p. 410.
} 
lo que se ha observado en el marco de una perspectiva tradicional en la comisión de las infracciones es que la determinación de dicho elemento alcanza mayor complejidad con la irrupción de las nuevas tecnologías de la información, y en este sentido, se convierte en un factor que debe ser considerado para repensar la imputación de la responsabilidad para estos casos.

Los prestadores de servicios de Internet, si bien no se les puede exigir que controlen todo el material que pasa a través de sus sitios web, sí deben ser responsables por el hecho de ofrecer alojamiento a material de información. La discusión aquí se puede abordar, por un lado, en términos de una necesidad de identificar los alcances que puede tener la responsabilidad y por otro, conectado a lo anterior, retoma un relieve especial la cuestión de si la responsabilidad civil debe reforzar su función preventiva antes que desplegar una función punitiva frente a la infracción del derecho de autor.

Como una respuesta al problema indemnizatorio de los daños derivados de infracciones al derecho de autor, el TLC entre Colombia y Estados Unidos consagra una línea ya trazada internacionalmente desde el ADPIC en 1994 que, a su vez, se inspira en la ley estadounidense de Copyright de 1976 (CA) ${ }^{91}$. De este modo, incorpora una reforma al sistema tradicional de la responsabilidad que más bien se encuentra basado en el principio de la reparación integral de los daños, y le atribuye una función predominantemente punitiva y preventiva de los daños derivados de infracciones a los derechos de autor.

Dada la vigencia del TLC en el ordenamiento colombiano, aún en deuda de ser implementado, el legislador y la jurisprudencia deben afrontar un nuevo modo de entender la responsabilidad civil a través de las funciones que ella puede cumplir para el control de las conductas en la sociedad. El campo del derecho autoral es más que un caso emblemático de la necesidad de que la indemnización puede llegar a tener un énfasis en la sanción y prevención de determinadas conductas que son rechazadas por la sociedad, debido al irrespeto de determinados derechos subjetivos y a sus implicaciones en el plano de la economía.

En cuanto a la era digital, se puede afirmar que ha repercutido en el estudio de la responsabilidad civil, toda vez que la concepción, en sentido material, que contiene la legislación en Colombia no es suficiente para asegurar la reparación de los daños en derechos de autor ocasionados en estos contextos, por lo que es necesario considerar la forma de aplicación de principios y criterios de sistemas foráneos que han demostrado cierta experiencia en el control de estas conductas infractoras.

Como se ha podido apreciar, el TLC es testimonio de cómo las políticas del derecho influyen en la adecuación de las reglas de la responsabilidad civil frente a las nuevas exigencias que plantean las infracciones al derecho de autor, en especial, aquellas que tienen lugar a través de Internet.

Para el caso concreto de Colombia, la incorporación de los fines preventivos de las legislaciones foráneas se podría implementar, entre otras cosas, con el cambio de paradigma de los jueces en revisar las características especiales de la conducta, no para imputar la

91 El artículo 504 de la CA de 1976 ha regulado la indemnización por infracción al Copyright y ha contemplado la facultad para el titular del derecho infringido para elegir entre una indemnización de los daños reales o la indemnización preestablecida que prevé la norma. 
responsabilidad, sino para graduar la pena. De esta forma, quien actúa con intención de lucrarse de la actividad ilícita deberá pagar una indemnización más alta respecto a quien lo hizo sin conocer que su actuar iba en contra de la ley.

Asimismo, el carácter punitivo podrá incorporarse en la legislación interna, dados los compromisos adquiridos con el TLC, a través de la figura de la indemnización preestablecida que permitirá que -sin tasarse la totalidad de los perjuicios- el juez cuente con cierta discrecionalidad para determinar la indemnización sin que sea necesario tasar los daños de forma total.

Ejemplificando, si una persona comparte por Internet una canción sin autorización del autor y/o titular, según los criterios de responsabilidad estipulados por la ley Colombiana, deberá retribuir - por concepto de daño- el valor comercial de los ejemplares reproducidos sin autorización. Aquí, para tasar la indemnización se desconoce el valor real de la obra pues generalmente, quien distribuye ilegalmente una canción en Internet lo hace de forma gratuita y en este orden de ideas, el infractor pagará una suma monetaria irrisoria que no lo disuadirá y tampoco castigará por su actuar.

De forma contraria, si se tuvieran en cuenta las funciones preventivas y punitivas de la responsabilidad, el juez podrá imponer como sanción aquella que emane de las características especiales de la conducta del infractor, y en algunos escenarios, que deberá estipular el legislador, podrá hacerlo sin tasar la totalidad de los daños ocasionados a la víctima.

De lo anterior se puede constatar por un lado, la necesidad de incorporar cambios a la responsabilidad civil para responder a las necesidades de la sociedad y por el otro, cómo elementos de legislaciones foráneas pueden servir de herramienta para este ejercicio.

Como reflexión final, en los términos de Monateri, se puede afirmar que "el derecho de la responsabilidad civil es una obra de ingeniería social comisionada a los intérpretes" ${ }^{22}$, quienes tienen la loable labor de ir señalando el sendero que mejor se ajuste a los intereses de las víctimas en la reparación del daño y de la sociedad en el control de las potenciales actividades generadoras de daños.

A propósito, es ilustrativo el ensayo de Busnelli titulado "la parábola de la responsabilidad civil"93 a través del cual el jurista livornés trata de sintetizar cuarenta años de estudios de la responsabilidad civil y donde, a través de la metáfora de un curso de agua en aumento, se llama la atención de los juristas que deben desarrollar un trabajo de contención para evitar el desborde de la institución. Es lo que toca al intérprete y juzgador colombiano en la tarea que le traslada el TLC para implementar el novedoso régimen de indemnización de los daños por infracción al derecho de autor.

\section{BIBLIOGRAFÍA CITADA}

Alvarado, Vivian (2002): "El derecho de autor en los Tratados administrados por la OMPI y en el Acuerdo sobre los Aspectos de los derechos de Propiedad Intelectual relacionados con el Comercio", en Organización Mundial de Intelectual intelectual, Seminario

\footnotetext{
92 MONateri (1998) p. 13.

93 Busnelli (1988) p. 658.
} 
de la OMPI para los paises andinos sobre la observancia de los derechos de propiedad intelectual en frontera (Bogotá, OMPI) pp. 2-30.

Albrieux, Sandrine (2004): La responsabilité des fournisseurs de moyens électroniques (París, Universitaire du Pont de Bois).

Alianza contra Piratería de Televisión Paga (2016): Situación de la piratería de la Televisión en Suramérica. Disponible en: http://www.alianza.tv: http://www.alianza.tv/files/ NetnamesAlianzaReport012016ES.pdf. Fecha de consulta: 28 de febrero de 2017.

Benahamou, Françoise \& Farchy, Joëlle (2009): Droit d'auteur et copyright (Paris: La Découverte).

Bensamoun, Alexandra (2010): "Retrato de un derecho de autor en crisis", RIDA, No 224: pp. 1-159.

Bercovitz, Rodrigo (2003): Manual de Propiedad Intelectual (Valencia, Tirant lo Blanch).

BÉTEILle, Lauren (2007): "Rapport sur le projet de loi de lutte contre la contrefacon", Doc. Sénat, No 420: pp. 30-120.

Binctin, Nicolas (2007): "L'évaluation des actifs immatériels peut-elle servir pour évaluer le prejudice?”, Cah. Dr. Entr. 2007, No 4: pp. 31- 378.

BusNeLli, Francesco (1988): "La parabola della responsbailità civile", RCDP: pp. 643-684.

Canaval, Juan Pablo (2008): Manual de propiedad Intelectual (Bogotá, Editorial Universidad del Rosario).

Caron, Christophe (2004): "Le défendeur "n’a pas été à même d'avoir connaissance de l'oeuvre première", Crónica JCP, No I: pp. 90-113.

Caron, Christophe (2013): Droit d'auteur et droit voisins (París, LexisNexis).

Chelsey, Karen (2010): "Calculating damages under the Digital Millennium Copyright Act: How far should courts go when multiplying statutory awards?", Journal of the Copyright Society of the U.S.A, No 54.: pp. 1-36.

Comunidad Andina de Naciones (2016): “QQué es la CAN?”. Disponible en: http://www. comunidadandina.org/Seccion.aspx?tipo=QU. Fecha de consulta: 1 de marzo de 2017.

Desideri, Jean-Pierre (2000): "La précaution en droit privé", D. 2000, Chron: pp. 238 -280 .

De Miguel, Pedro (2015): Derecho Privado de Internet. Cuarta edición (Navarra, Civitas).

ERdozain, José (2002): Derechos de autor y propiedad intelectual en Internet (Madrid, Tecnos).

Esteve, Lydia (2006): Aspectos internacionales de las infracciones de derechos de autor en Internet (Granada, Editorial Comares SL).

FICSOR, Mihály (2002): The Law of Copyright and the Internet. The 1996 WIPO Treaties, their Interpretation and Implementation (New York, Oxford University Press).

Gaubiac, Yves (1995): "Une dimension internacional nouvelle du droit d'auteur, l'Accord sur les aspects des droits de propriété intellectuelle qui touchent au commerce”, RIDA, No 166: pp. 7-34

Gautier, Pierre (2004): Propriété litéraire et artistique (París, Presses Universitaire de France).

GinsBuRG, Jane (1991): "Historia de dos derechos de autor: la propiedad literaria y artística en la Francia y la América revolucionarias”, RIDA, No 147: pp. 124-167. 
Heiner, Ronald (1986): "Imperfect Decisions and the Law: On the evolution of Legal Precedent and Rules", Journal of Legal Studies, N 15, pp. 227-261.

IzQuierdo, Andrés \& PAlacio, Gustavo (2011): "Un acercamiento comparado sobre la implementación de los ADPIC para la observancia de los derechos de propiedad intelectual en Europa, Estados Unidos y Colombia”, Revista de Derecho Privado, No 46: pp. 1-39.

Jiménez, Héctor, Borja, Martín \& PalaO, Iñigo (2015): "Observatorio de piratería y hábitos de consumo de contenidos digitales 2014”. Disponible en: http://www.fap.org.es/ images/observatorios/pdf/Observatorio\%20pirateria\%202014.pdf. Fecha de consulta: 27 de febrero de 2017.

Kaplan, Lewis (2003): "Copyright and the Internet", Temple Environmental Law \& Technology Journal, Vol. 22, Issue 1: pp.1-14.

Kessler, Anne (2000): "Présomptions et droit d'auteur”, Paris-Sud, No. 154: pp. 203-289

LEÓN, Édgar \& VARELA, Eduardo (2015): Ilegalidd aparente o violación permanente: los derechos de autor y las tecnologías P2P (Bogotá, Editorial Universidad del Rosario).

LemLeY, Mark (1997): "Dealing with Overlapping Copyrights on the Internet”, University of Day-ton Law Review, Vol. 22: pp.547-585.

Lipszyc, Delia (2004): Nuevos temas de derecho de autor y derechos conexos (Bogotá, CERLALC).

LiPSZYC, Delia (2006): Derechos de autor y derechos conexos (Bogotá, Centro Regional para el Fomento del Libro (CERLALC)).

Lucas, Henri-Jacques, LuCAS, André \& LuCAS-Schloetter, Agnès (2012): Traité de la propriété littéraire et artistique (París, LexisNexis).

Mallet-Poujol Natalie (1999): "Vie privée et droit à l'image: Les franchises de l'histoire", Dans LEGICOM, N²0: pp. 51-68.

MAsouYÉ, Claude (1978): "Guide to the Berne Convention for the Protection of Literacy and Artistic Works". Disponible en: ftp://ftp.wipo.int/pub/library/ebooks/wi popublications/Guide-Berne-Convention-wipopub615E.pdf. Fecha de consulta: 17 de febrero de 2017.

MatTHEWs, Duncan (2002): Globalising Intellectual Property rights (London, Routledge).

Monateri, Pier Luigi (1998): La responsabilità civile, en SACCO, R, Trattato di diritto civile (Turín, Utet) pp. 13-58.

Morales, Marcos (2007): Elementos de responsabilidad extracontractual en materia de marcas comerciales, en Morales, M, Temas actuales de propiedad intelectual. Estudios en homenaje a la memoria del profesor Santiago Larraguibel Zavala (Santiago de Chile, Legal Publishing) pp 357-384

Ово́n, Juan (2009): "Infracciones al derecho de autor y los derechos conexos en el entorno digital", Revista iberoamericana de derecho de autor, Año III, No 6: pp. 110-129.

Organización Mundial de la Propiedad Intelectual (2015). "Estudio sobre la piratería: "El mercado sobrante en México”." Disponible en: http://www.wipo.int/edocs/mdocs/ enforcement/es/wipo_ace_10/wipo_ace_10_12.pdf. Fecha de consulta: 17 de febrero de 2017

PASSA, Jérôme (2006): Droit de la propriété industrielle (París, LGD).

Pauner, Cristina (2014): Manuales: Derecho de la información (Valencia, Tirant lo Blanch). 
Pérez, Jorge (2008): La gobernanza en Internet. Contribución al debate mundial sobre la gestión y el control de la red (Madrid: Grupo Planeta).

PlatA, Luis (2010): Responsabilidad civil por infracciones al derecho de autor (Barranquilla, Ediciones Uninorte - Grupo Editorial Ibáñez).

Plata, Luis (2010): "El concepto de conducta como elemento indispensable en la Responsabilidad Civil por Infracciones al Derecho de Autor", Revista de Derecho, No 34: pp. $79-115$.

PlazA, Javier (2002): Propiedad Intelectual y Sociedad de la Información (Navarra, Editorial Aranzadi SA).

Ромво, Luis (2015): Estándares de valuación de activos intangibles de propiedad intelectual (Bogotá: Universidad Externado de Colombia).

Ponzanelli, Gulio (1992): La responsabilità civile. Profili di diritto comparato (Bologna, Il Mulino).

Ribera, Begoña (2009): "La infracción de derechos de autor a través de los sistemas peer to peer y peer to mail", Revista Iberoamericana de derecho de autor, Año III, No 6: pp. 3861.

RodotÀ, Stephano (1964): Il problema della responsabilità civile (Milanor, A. Giuffré).

Rogel, Carlos (2003): Estudios completos de propiedad intelectual, Volumen cuatro (Madrid, Reus SA).

SANCHIS, María Trinidad (2004): Derechos de autor, digitalización e Internet (Madrid, Editorial Universitas SA).

Schechter, Roger \& Thomas, John (2003): Intellectual Property. The Law of Copyrights, Patents and Trademarks (New York: Thomson West).

Schuck, Peter (1991): Tort Law and the Public Interest. Competition Innovation and Consumer Welfare (New York, W. W. Norton \& Company).

SChuster, Santiago (2008): "Los presupuestos necesarios para una gestión colectiva en el ámbito digital", Revista Iberoamericana de derecho de autor, Año II No 3, enero-junio: pp. 13-35.

SirInelli, Pierre (2000): Le droit d'auteur à l'aube du troisième millénaire (París: JCP).

Varela, Eduardo (2009): Tecnologías peer-to-peer, derechos de autor y Copyright (Bogotá, Editorial Universidad del Rosario).

Visintini, Giovanna (1999): Tratado de la responsabilidad civil, Tomo I y II (Buenos Aires, Astrea).

Woolcott, Olenka \& Flórez, Germán (2015): Protección del derecho de autor (Bogotá, Astrea).

Woolcott, Olenka \& Flórez, Germán (2014): "El régimen de exención de responsabilidad de los ISP por infracciones de propiedad intelectual en el TLC Colombia-Estados Unidos: una explicación a partir de la DMCA y la DCE”, Revista Vniversitas, No 139: pp. 385-416.

Zapata, Fernando (1998): "Las nuevas tecnologías. Desafíos para el derecho de Autor", Dikaion, No 7: pp. 137-145. 


\section{NORMAS CITADAS}

Acuerdo sobre los Aspectos de los Derechos de Propiedad Intelectual relacionados CON el Comercio (ADPIC) (15/04/1994).

CA Paris, 31 de octubre 2000. Comm. Сom. Électr (2001).

Código Civil de Colombia (15/4/1887).

Convenio de Berna (4/5/1986).

Decisión 351 de la Comunidad Andina (17/12/1993).

Ley 23 Sobre derechos de autor (28/1/1982).

Tratado de la OMPI sobre Derecho de Autor (20/12/1996).

Tratado de la OMPI sobre InTerpretación o EJeCución y Fonogramas (20/12/1996).

\section{JURISPRUDENCIA CITADA}

Sentencia del Proceso No. 24 IP de 1998 Tribunal de Justicia de la Comunidad Andina. Sentencia del Proceso No. 177-IP-2013 del Tribunal de Justicia de la Comunidad Andina. 